\title{
The (in)visible barriers to free software: Inequalities in online communities in Spain
}

Dafne Calvo, University of Valladolid, Department of Early Modern History, Modern History and History of America, Journalism and Audiovisual Communication and Advertising, Spain

dafne.calvo@uva.es

\begin{abstract}
Free culture communities support self-learning, peer production, and the distribution of knowledge generated without any restrictions. However, free culture communities are not isolated from the social inequalities of the outside world. Understanding (in)visibility as the (in)ability to address internal under-representation within these communities, this research aims to analyse their member profiles and their perception of this issue. To this end, an online questionnaire was administered to 290 communities and interviews were conducted with members of 37 of these previously surveyed communities. The respondents and interviewees acknowledged that technopolitics requires a broad knowledge of the technical implications of their values, which makes access to and participation in a community more difficult. They also criticised the gender bias of their communities and, last but not least, pointed to other inequalities relating to the sexual orientation, socioeconomic level, or ethnic origin of the members of their communities.
\end{abstract}

\section{Keywords}

free culture, free software, gender inequalities, (in)visibility, knowledge divide, age divide, social movements, participation

\section{Introduction}

Optimistic perspectives regarding the liberating potential of information and communication technologies (ICTs) have accompanied the Internet since its advent. Under the concept of digital commons, free software and free culture groups have organised themselves in favour of self-learning, peer production, the distribution of knowledge, and universal access to technological devices (Benkler, 2006; Himanen, 2001; Ostrom, 1990). Albeit older, the free software movement is embedded in free culture, since the latter concept involves a broader understanding of knowledge to be created and distributed, including the code of computer programs. Privacy is also one of the frequent topics in these communities, for which personal data protection facilitates individual autonomy and freedom of communication on the Internet (Bauman et al., 2014; Coleman, 2011; Solove, 2001).
The accelerated development of the Internet and the expanding individual use of technological devices have created a new public sphere that facilitates anonymous interaction within specific social groups (Lessig, 2004; Rheingold, 1993). Studies of social movements have also traditionally linked the concept of (in)visibility to their capacity to present their specific demands and discursive frameworks as regards the political agenda in both the mass media and on new online platforms (Sobieraj, 2010; van Stekelenburg, Oegema, \& Klandermans, 2010). Visibility in the media is thus understood as the ability to influence the public discourse and as the potential media impact that the slogans and vindications of social movements may have (Koopmans, 2004).

Consequently, so as to protect themselves from online monitoring these free software communities call into question the traditional concept of visibility as the ability to be included in the public sphere (Dahlberg, 2018). In this sense, (in)visibil- 
ity is a process of renegotiation in which social movements "try to control their visibility and invisibility" (Vaserfirer, 2012, p. 624) depending on the context, their tactical strategies, and their objectives.

Some research has questioned the ideal of text-based and anonymous participation, as not having information on contributors may prevent communities from giving visibility to their under-representation, their members' personal experiences, and the bias of their productions (e.g., source code) (Collier \& Bear, 2012; Costanza-Chock, 2018). According to Nafus (2012, p. 669), "patches don't have gender", thus expressing the tensions perceived between the assumed anonymity of contributors to free software projects and the existing inequalities within these groups.

Understanding visibility as having a presence in the public sphere, some studies have noted that people with specific sociodemographic profiles (e.g., white men) monopolise representative roles and are thereby more visible (Rohlinger, Redmond, \& Stamm, 2019). This discussion also connects to the free software movement. Although decentralisation is one of the core values of these communities, scholars have already cautioned that, more often than not, a group of experts controversially takes on a representative and leadership role in initiatives of this type (Giuri, Rullani, \& Torrisi, 2008; Jordan, 1999).

In this study, (in)visibility is understood as the ability to address under-representation in these communities (Crenshaw, 1991; Stoecker, 1995). From the point of view of intersectionality, different studies have analysed the connections between social struggles and the inclusion of more transversal visions of the demands made by social movement, for instance, LGBTQI and feminism, environmentalism and social class, as well as anti-racism and gender (Abdi \& Van Gilder, 2016; Magnusdottir \& Kronsell, 2015; Milan \& Treré, 2019; Patil \& Purkayastha, 2015; Seymour, 2019).

Due to the influence of $15 \mathrm{M}$ protests, the Spanish free culture movement is closely associated with the global jus- tice movement and social rights struggles (Postill, 2016). This development has made a dramatic contribution to disseminating the concept of technopolitics (Treré \& Barranquero, 2018), namely, the tactical use of digital tools for collective action (Toret et al., 2013), as well as the sociological interpretation of technologies (Sádaba \& Gordo, 2011). Owing to the characteristics of the Spanish context, it is particularly relevant not only to identify the (in)visibility gaps in communities, but also to understand how they themselves can interpret (in)visibility problems and devise tactics to deal with them.

Accordingly, an approach is taken here to the (in)visibility debate in free software and free culture communities. In light of the results of the quantitative questionnaire administered to these communities, the first step involves analysing the possible under-representation in them concerning four specific aspects, to wit, gender, age, educational level, and technological expertise. This is followed by a discussion on the causes, consequences, and possible solutions regarding access barriers to their projects. The intention is to address the (in)visible barriers existing in a movement that values universal access to knowledge. Even though code has no gender - nor age or educational level technology is built on previous structures of inequality and under-representation that should be explored (Costanza-Chock, 2018; Margolis, Fisher \& Miller, 1999; Nafus, 2012; Reagle, 2013).

\section{Inequality issues in the free culture movement}

In contrast to the ideal of contributors' invisibility in culture and free software projects - that is, personal data privacy as one of their core values - several approaches have reflected on the archetypal member profile of these communities. These analyses have been useful for highlighting current under-representation in these communities and the extent to which this unequal structure affects the movement's participation and internal dynamics 
(Hill \& Shaw, 2013; Powell, Hunsinger, \& Medlin, 2010; Reagle, 2013).

As for gender, some studies have shown that women contribute less to free knowledge than men. Several surveys have even reported a female presence of below two per cent in free software and free culture projects (Ghosh, Glott, Krieger, \& Robles, 2002; Hill \& Shaw, 2013; Robles, Reina, Serebrenik, Vasilescu, \& González-Barahona, 2014). For example, both women and cultural products mostly consumed by them (e.g., television series, specific books, etc.) have less presence on Wikipedia. Additionally, entries on historically or socially relevant women are shorter and their biographies include more references to their romantic relationships (Graells-Garrido, Lalmas, \& Menczer, 2015; Reagle \& Rhue, 2011; Wagner, Garcia, Jadidi, \& Strohmaier, 2015).

The critical analysis of these data offers insights into the internal dynamics of these communities and the broader gender inequalities of contemporary societies as relevant factors in their composition. In the main, women devote less free time to contributing to free software and free culture projects. Besides, their lack of self-confidence in maths, engineering, technology, and science, affects their willingness to participate in these communities (Collier \& Bear, 2012). Similarly, the propensity of women to participate in collaborative work and to avoid the often competitive environments of technological communities has led to a lower level of engagement (Antin, Yee, Cheshire, \& Nov, 2011; Lam et al., 2011; Powell et al., 2010). In addition, they have sometimes claimed to have been the target of harassment and other types of symbolic violence (Nafus, 2012).

Some research has noted an early interest in technology and free software, especially among men (Lim \& Kwon, 2010; Powell et al., 2010; Robles et al., 2014). The survey of 2784 developers conducted by Ghosh et al. (2002) shows that most people joining a community are aged between 16 and 36 . They point out that free software is an essential topic for the younger generations, while putting this tendency down to aspects such as technological breakthroughs and the market development of software products. Since the 1990s, access to computers and other devices from an early age has encouraged people to inquire into programming and to socialise in virtual communities (Ghosh, 2005; Margolis et al., 1999).

These findings contradict those of studies that point to a generational change in the perception of technological issues such as privacy, defended by free software communities. It is the youngest Internet users who have a better grasp of the implications of participating in mainstream social networks, but they also engage in more online activities and disclose their information more frequently (Nosko, Wood, \& Molema, 2010; Taraszow, Aristodemou, Shitta, Laouris, \& Arsoy, 2010). This behaviour could be related to factors such as the more technologically ubiquitous context in which the younger generations have grown up (Raynes-Goldie, 2010) and their greater tolerance to personal life issues such as sexual orientation (Tufekci, 2008). The results of studies of the early interest in technology and free software support views such as that held by Fuchs (2011), who criticises the discourse that describes young people as irresponsible and less informed, given that it is a one-dimensional argument that presupposes that they are incapable of resolving social problems.

Furthermore, the free software movement has been characterised by hacker ethics (Himanen, 2001), which proposes a learning process through the curious and enthusiastic interaction with technological devices. This principle connects with the scientific literature addressing the educational dimension of social movements as entities with the capacity to generate knowledge on their own (Casas-Cortés, Osterweil, \& Powell, 2008; Cox \& Flesher Fominaya, 2009; Della Porta \& Pavan, 2017; Stephansen, 2016). Barbas and Postill (2017) identify those practices of learning from the experiences of counterparts unrelated to commercial and state institutions with those of $15 \mathrm{M}$ activists in Spain. 
As to the academic qualifications of community members, it had been contended that those contributing to source codes usually possess a high level of technical training, for which reason those with weaker technological skills limit themselves to undertaking tasks aimed at motivating or galvanising their communities (Coleman \& Golub, 2008; Jackson \& Kuehn, 2016). In this type of community, the most common qualifications are $\mathrm{PhDs}$ and Master's and Bachelor's degrees, usually specialising in software engineering, programming, or telecommunications (Ghosh et al., 2002).

Coding and designing digital tools are often the main activities of these technological communities, which require prior training (Castells, 2012; Coleman, 2011; Jordan, 2017; Langman, 2006). Therefore, the possibilities of protecting themselves against online monitoring are limited, as only a small number of Internet users are familiar with these tools and techniques (Carr, 2008; Christl \& Spiekermann, 2016; Reischl, 2008). Projects dedicated to generating Creative Commons (CC) content require a higher degree of abstraction and a more solid cultural background, all of which means that participants, as well as having a high level of knowledge, must put a lot of interest and effort into them (Benkler, 2006).

The spaces and initiatives of political resistance emerging as a result of these previously perceived inequalities have suggested conscious intersections between technological sovereignty and social movements, such as feminism, anti-racism, and LGBTQI (Costanza-Chock, 2018; Milan \& Treré, 2019; Toupin, 2014, 2016). Beyond the differences deriving from technical and technological knowledge in the free culture movement, these projects propose a reflection on the values of freedom and openness, while claiming that under-representation is not unavoidable, but that communities must make inequalities visible and seek solutions that break down the barriers to free culture and technology (Reagle, 2013).

\section{Design and methods}

The aim of this paper is to approach the representation and (in)visibility of diversity in free software and free culture communities in Spain. To this end, the following three research questions have been formulated: a) What is the archetypal member profile of these communities?; b) How do these communities interpret their internal composition?; and c) What strategies do they implement to foster greater diversity in their organisations?

To answer these research questions, a combined methodology with two phases was employed. The first phase involved administering an online questionnaire to several Spanish communities revolving around the values of free culture. Since the sample was not previously defined (Cea D'Ancona, 1996; Howard, 2002), the anthropological snowball technique was used to identify 739 different communities susceptible to being included in the study, given that they met the four basic criteria established for sampling, inspired by the study performed by Barranquero and Montero (2015). Specifically, the sample included those communities that a) had been previously and explicitly identified with free software and free culture, b) operated in Spain, c) were at least one year old, and d) were neither private companies nor public administrations. The questionnaire, which included four items relating to the member profile, especially regarding gender, age, educational level, and technological expertise, was sent to each community included in the sample.

All the questions were closed-ended. The item relating to the educational level of community members was based on the categories established by the Spanish Ministry of Education and Science (2006): preand primary school education; secondary school education and vocational training; and higher education. Four activists were interviewed in a pre-test, while the questionnaire per se was completed by the activists of 290 communities (Calvo, 2015).

In the second phase, 37 of the communities that had previously formed part of the survey were contacted. Intentional 
Table 1: Intentional sample of free software communities $(n=37)$

\begin{tabular}{|c|c|c|c|c|}
\hline Community & Location & Data & Type & Duration \\
\hline Akelarre Ciberfeminista & Castile and Leon & 09/2018 & Group & $159^{\prime}$ \\
\hline Wikimedia España & Castile and Leon & 09/2018 & Group & $159^{\prime}$ \\
\hline Bit:LAV & Castile and Leon & 09/2018 & Group & $159^{\prime}$ \\
\hline Ondula & Madrid & $10 / 2018$ & One-to-one & $66^{\prime}$ \\
\hline Cuarto Propio en Wikipedia & Madrid & $10 / 2018$ & Group & $115^{\prime}$ \\
\hline la_bekka & Madrid & $10 / 2018$ & One-to-one & $127^{\prime}$ \\
\hline Vivero de iniciativas ciudadanas (CIVICS) & Madrid & $10 / 2018$ & One-to-one & $18^{\prime}$ \\
\hline Avfloss & Madrid & $10 / 2018$ & Group & $133^{\prime}$ \\
\hline Asociación Hackerspace Valencia & Valencia & $11 / 2018$ & One-to-one & $86^{\prime}$ \\
\hline Valencia TechHub & Valencia & $11 / 2018$ & One-to-one & $86^{\prime}$ \\
\hline ValenciaJS & Valencia & $11 / 2018$ & One-to-one & $54^{\prime}$ \\
\hline FabLab Valencia & Valencia & $11 / 2018$ & One-to-one & $54^{\prime}$ \\
\hline Makers UPV & Valencia & $11 / 2018$ & Group & $113^{\prime}$ \\
\hline Asociación gvSIG & Valencia & $11 / 2018$ & One-to-one & $60^{\prime}$ \\
\hline FabLab Cuenca & Castile-La Mancha & $11 / 2018$ & One-to-one & $92^{\prime}$ \\
\hline Panorama 180 & Catalonia & $11 / 2018$ & One-to-one & $88^{\prime}$ \\
\hline Hackers at UPC & Catalonia & $11 / 2018$ & One-to-one & $63^{\prime}$ \\
\hline i-LabSo SCCL & Catalonia & $11 / 2018$ & One-to-one & $56^{\prime}$ \\
\hline Barcelona Bitcoin Community & Catalonia & $11 / 2018$ & One-to-one & $87^{\prime}$ \\
\hline Asociación Blockchain Catalunya & Catalonia & $11 / 2018$ & One-to-one & $87^{\prime}$ \\
\hline pyBCN & Catalonia & $11 / 2018$ & Group & $78^{\prime}$ \\
\hline pyladiesBCN & Catalonia & $11 / 2018$ & Group & $78^{\prime}$ \\
\hline Eticas Foundation & Catalonia & $11 / 2018$ & One-to-one & $61^{\prime}$ \\
\hline Python España & Catalonia & $11 / 2018$ & One-to-one & $86^{\prime}$ \\
\hline Aeropython & Catalonia & $11 / 2018$ & One-to-one & $86^{\prime}$ \\
\hline Pybonacci & Catalonia & $11 / 2018$ & One-to-one & $86^{\prime}$ \\
\hline Made Makerspace Barcelona & Catalonia & $11 / 2018$ & One-to-one & $61^{\prime}$ \\
\hline Autofabricantes & Catalonia & $11 / 2018$ & One-to-one & $70^{\prime}$ \\
\hline Llefi@Net & Catalonia & $11 / 2018$ & Group & $120^{\prime}$ \\
\hline Caliu & Catalonia & $12 / 2018$ & Group & $61^{\prime}$ \\
\hline Colectic SCCL & Catalonia & $12 / 2018$ & One-to-one & $62^{\prime}$ \\
\hline CCCBLab & Catalonia & $12 / 2018$ & Group & $122^{\prime}$ \\
\hline Barcelona Free Software & Catalonia & $12 / 2018$ & Group & $61^{\prime}$ \\
\hline Som Connexió & Catalonia & $12 / 2018$ & One-to-one & $71^{\prime}$ \\
\hline Expansió de la Xarxa Oberta (eX0) & Catalonia & $12 / 2018$ & Group & $163^{\prime}$ \\
\hline Drupalcat & Catalonia & $12 / 2018$ & One-to-one & $56^{\prime}$ \\
\hline Educaires & Catalonia & $12 / 2018$ & Group & $60^{\prime}$ \\
\hline
\end{tabular}

sampling was employed to select the communities, including those with different projects as regards their location, objectives, activities, and participant numbers, with a view to creating participatory spaces enriched with diverse perspectives and knowledge of the object of study (Ander Egg, 2003; Ruiz Olabuénaga, 2012).

The interviews were conducted offline with between one and eight people from the same community (see Table 1), the number of interviewees per community depending on their availability. Neither one-to-one interviews nor group interviews were structured around a set of standard questions, meaning that they adopted the form of deliberative interviews (Cuesta, Font, Ganuza, Gómez, \& Pasadas, 2018), in which the activists discussed the 
quantitative data gathered beforehand. This methodological decision served the purpose of addressing participatory research that generates knowledge through collective dialogue between researchers and activists (Casas-Cortés et al., 2008; Cox \& Flesher Fominaya, 2009; Cox, 2014).

At the beginning of the interviews, the activists were provided with a printed document with the results so that they could discuss them. In attempt to avoid the author's logic and to reflect their interpretations and testimonies accurately, the interviewees were only offered guidelines occasionally (Durston \& Miranda, 2002; Lima Santos, 1983). To ensure their privacy (Valles, 1999), the interviewees' names were anonymised with a random number.

\section{Results}

In what follows, the research question regarding the archetypal member profile of the communities surveyed will be addressed first on the basis of the quantitative data obtained. Following this and based on the results of the qualitative study, the other two research questions will be broached.

\subsection{Quantitative data on the communi- ties' under-representation}

The quantitative survey among the members of 290 communities provides insights into the member profile of free software communities in Spain (Table 2). Firstly, women and people with non-binary gender identities accounted for less than 30 per cent of respondents, while 71 per cent were men. Secondly, almost half of the respondents were in the 35 to 44 age group and there were only a few people younger than 25 or older than 54. Lastly, 91 per cent of the respondents declared that they held an academic degree or a higher vocational training. Only nine per cent indicated that they had only completed primary or secondary education. In this sense, the members of university student associations had not yet completed their studies, whatever the level. Those with only a primary school education or with less than five years of schooling were conspicuous by their absence in the sample. Concerning expertise in technical and technological disciplines, 60 per cent confirmed that they had studied mechanics, electronics, computer science, or telecommunications while 17.6 per cent studied other fields but had some contact with technological fields. Finally, 19 per cent stated that they had no specific training. These quantitative data will be discussed in further detail in the following section.

Table 2: Descriptive survey results $(n=290)$

\begin{tabular}{|c|c|c|}
\hline \multicolumn{3}{|l|}{ Gender } \\
\hline \multicolumn{2}{|l|}{ Male } & 71.0 \\
\hline \multicolumn{2}{|l|}{ Female } & 20.7 \\
\hline \multicolumn{2}{|l|}{ Other genders } & 2.1 \\
\hline \multicolumn{2}{|l|}{ DK/NA } & 6.2 \\
\hline \multicolumn{3}{|l|}{ Age } \\
\hline \multicolumn{2}{|l|}{ From 18 to 24} & 3.8 \\
\hline \multicolumn{2}{|l|}{ From 25 to 34} & 28.6 \\
\hline \multicolumn{2}{|l|}{ From 35 to 44} & 46.9 \\
\hline \multicolumn{2}{|l|}{ From 45 to 54} & 14.5 \\
\hline \multicolumn{2}{|l|}{ From 55 to 64} & 2.8 \\
\hline \multicolumn{2}{|l|}{65 and over } & 0.0 \\
\hline \multicolumn{2}{|l|}{ DK/NA } & 3.4 \\
\hline \multicolumn{3}{|l|}{ Educational level } \\
\hline \multirow{4}{*}{ Basic education } & Less than five years of schooling & 0.0 \\
\hline & Primary school & 0.0 \\
\hline & Secondary school & 0.7 \\
\hline & Post-secondary education & 2.4 \\
\hline \multirow[t]{3}{*}{ Intermediate education } & Intermediate vocational training & 0.7 \\
\hline & Higher vocational training & 13.4 \\
\hline & Bachelor's degree & 37.6 \\
\hline \multirow{5}{*}{ Higher education } & Master's degree & 26.9 \\
\hline & $\mathrm{PhD}$ & 8.6 \\
\hline & Postgraduate studies & 4.5 \\
\hline & Other & 1.0 \\
\hline & DK/NA & 4.1 \\
\hline \multicolumn{3}{|l|}{ Techn. expertise } \\
\hline \multicolumn{2}{|l|}{ Yes } & 60.0 \\
\hline \multicolumn{2}{|l|}{ Some } & 17.6 \\
\hline \multicolumn{2}{|l|}{ No } & 19.0 \\
\hline \multicolumn{2}{|l|}{ DK/NA } & 3.4 \\
\hline
\end{tabular}




\subsection{The (In)visibility issue in free software communities}

Regarding the qualitative interviews, a look is first taken at how the groups interpreted their internal composition based on the quantitative survey findings. Secondly, the focus is placed on the strategies that they implemented to foster greater diversity in their organisations. In the following, these issues are first addressed in terms of gender and then in terms of age, technological expertise, and education.

\subsubsection{Gender}

The interviewees generally identified with the description of an archetypal technopolitical profile: "I'm not surprised at all [about the quantitative survey results]. Unfortunately, I'm not surprised" (Interview 25); and "Yes, unfortunately, it reflects our case" (Interview 27). In terms of gender, some of the interviewees even interpreted the survey findings as a positive reflection of reality: "If you'd told me the proportion was 80 per cent, I wouldn't have been surprised either" (Interview 1); and "In one event we had no women speakers. In software organisations, this percentage is very optimistic. [...] The situation of free software is critical" (Interview 4).

The interviewees pointed out that women access the field of technology from other areas such as law, cultural management, education, biology, geology, and business administration. "My impression is that when it hasn't strictly to do with free software, the numbers change" (Interview 6). Although women are present in critical thinking spaces addressing social problems and the negative impact of technologies, their visibility in positions of representation is scarce:

The world of technology's occupied by men, especially in certain projects. There're very few women among the free software gurus. (Interview 24)

Some interviewees declared that women had had a greater presence in the movement during the 1990s and the early $21^{\text {st }}$ century. At the same time, they felt that the proportion of women in computer sci- ence had decreased as soon as it was considered to be an engineering degree:

In the $21^{\text {st }}$ century because they tell us 'There you go, women don't want to be engineers!' Yes, we do; we have always wanted to be [engineers. (Interview 26)

The interviewees regretted that technopolitical participation reflected the bias in current university courses and the tech industry. Be that as it may, for some of the interviewees this inequality was more down to gender than culture:

Geeks tend to be always boys rather than girls, right? [...] They have less interest than men. (Interview 20)

In other cases, the interviewees held that gender inequalities in their communities were the result of schooling and pre-existing stereotypes, gender roles, and macho attitudes, for which reason they claimed that there was a need to generate safe spaces for women. They recognised that men sometimes monopolised debates and did not facilitate collaboration or offer assistance when addressing more technical issues. They also reported that there were incidents of symbolic violence and harassment against women that hindered their access to this type of community:

\footnotetext{
I've seen it in companies where the entire team of developers are men, and they interview a woman for any position. The answer is, 'Hire that one because she's hot.' That's commonplace. Women aren't deaf and it's not very motivating. (Interview 16)
}

Along with their self-critical stance, the interviewees also recognised that the feminist movement had recently pushed for promoting gender equality and the visibility of women in all social spaces. Sensitive to the new social context, communities have developed various practices to tackle this problem. Regarding strategies fostering greater diversity in their organisations, the interviewees hinted at various aspects. Some indicated that their communities 
had internally assumed feminist principles to avoid the feminisation of specific group assignments, namely, those relating to community building tasks. For instance, they created temporary representation and decision-making positions or tried to ensure that women led public activities and media coverage.

Another standard method for fostering women's participation was the promotion of activities exclusively for them in order to provide them with their own spaces, thus highlighting their presence, insofar as they tended to be invisible in larger groups in which men made up the majority. Some events focused on schoolgirls with the mission of "awakening technological vocations" and "empowering girls so that later they feel like [...] so that they can opt for this type of career" (Interview 21). They also encouraged the participation of women in events, either prioritising their registrations or proposing them as participants:

We've organised some virtual webinars, and this year we've decided that the speakers should all be women. Although they are small activities, the idea is to give them visibility. (Interview 24)

Some communities collaborated with female-only groups, with the intention of appealing directly to female participants:

I realise that when you send them messages, the community responds very well. In other words, when you send things directly to women, they become a lot more involved. (Interview 2).

With a similar strategy, some communities had decided to generate parallel communities in which the proportion of women was above 50 per cent so as to create more diverse environments under the values of mediation and care:

A little bit of the atmosphere they [women] reject is sometimes generated in the more masculine communities, as they are more competitive than collaborative. So, a more collaborative type of event seemed more welcoming to them. (Interview 2)

Communities also drafted codes of conduct aimed at eradicating sexist behaviour and, more generally, safeguarding the diversity of these spaces. These included a set of rules on acceptable and unacceptable conduct at meetings, conferences, workshops, and courses, such as respect for minority groups or the explicit prohibition of harassment. One code even set out the steps that should be taken in such an event:

It [the code of conduct] also states, 'If any of the people who are at this event or participating in the community display any of these behaviours, we shall notify the person in charge and take immediate action'. (Interview 4)

Even when they took a feminist stance, not all the interviewees confirmed that they carried out specific actions aimed at combating gender bias in their communities. At the same time, they recognised that some community members were reluctant to establish rules or to create technology-specific groups with an explicit gender standpoint. However, they declared that disseminating a discourse and values grounded in feminist principles in masculinised environments had a transforming impact on these communities.

\subsubsection{Age, technological expertise, and education}

The quantitative results as regards age gave rise to more controversy than those regarding gender. Several interviewees did not identify with them since their communities were formed by adults or were more diverse:

It's quite heterogeneous. Some people aren't even 20, and others are over 55. Younger people are always joining. The young people we meet are already very aware and have a very critical point of view. We're thrilled with that (Interview 27) 
ome interviewees also believed that there were fewer young people in their communities due to Spain's ageing population. For this reason, not so many young people participated in the survey. Similarly, key members completing the questionnaire tended to have belonged to their communities for longer, tended to play representative roles, and tended to be older. Furthermore, the interviewees felt that the organisation of political projects, whether technological or not, required more maturity. They also stated that political positioning resulted from having stronger ties with the social environment and from specific political experiences:

Because when you're under 24, rather than getting involved in activism, you want to have fun. When you're a few years older, you say, 'Holy shit, I'm sick of parties. I've had enough of being a drinking buddy. Come on, let's do other things'. (Interview 17)

Concerning the technological training of the younger generations, other respondents expressed their concern about the lack of interest in politics, warning that the knowledge and use of technological devices and social networking sites did not imply their critical questioning. In their view, even though young people believed that they knew the Internet inside out, they failed to identify the violation of their rights in the online environment through practices such as datafication or the use of decision-based algorithms:

The new generations have much more difficulty acquiring a critical awareness. Google was there before them, and then the online world was like that already, so, when no one challenges technologies in their educational system, there's no critical questioning. (Interview 8)

The generation born after the mid-1980s grew up with fast-paced technological development and experienced the boom of electronic devices for private use, the Internet, and the Web 2.0. Historically, the movement of free culture and free software was not a thing of millennials, but of past generations. Therefore, this begs the question of whether or not this social activism has left a legacy to later generations:

Yes, they're movements that have been quite powerful in the past, but they are simply not engaging the next generations. There's something we haven't got right there. (Interview 20)

Accordingly, the interviewees declared that it was necessary to plan educational activities for children in order that they should be more aware of the uses to which they put technologies.

As to academic qualifications, the interviewees recognised that there was a tendency for people with higher education to run these projects. They understood that the training curve in some projects required a comprehensive understanding of free software and free culture movements. All of which meant that attracting people with lower qualifications was a challenge. At this point, the interviewees compared themselves with other movements, such as those relating to animal protection or ecology, in which technical skills were not a prerequisite for political participation. The complexity of the online environment and the social problems associated with it prevented larger sectors of society from becoming involved:

\begin{abstract}
It's very easy to join a community aimed at promoting vegetable consumption. You join, buy your vegetables, and then you've saved the world. However, in our project, there're a thousand things that must be considered; some problems just freak you out. (Interview 17)
\end{abstract}

The interviewees were against this trend, recognising that establishing minimum academic requirements limited access to their communities. They understood that one of the aims of free culture was to break down educational barriers to knowledge sharing, while believing self-learning was a method that surpassed formal training. Notwithstanding the results of the quantitative survey, they felt that holding a diploma or not was a minor issue when it came 
to the ability to code, digitally generate or publish copyleft content:

Academia doesn't recognise a certain type of knowledge, but we treat each other as equals, regardless of our educational level or profession. (Interview 21)

However, self-learning processes also implied prior empowerment, which could be a barrier for people with less technical knowledge and skills. Some interviewees also acknowledged that as it was often impossible for someone of the same sex to act as a mentor in the self-training process in masculinised communities, this might have led to there being fewer women:

I believe that it's even harder for a woman. Because when I say, 'It's okay' [understood here as an expression of encouragement], I get to create a stronger supportive relationship with a man than with a woman because I am a man. (Interview 17)

Once again, the lack of specific mediation processes for women contributed to their under-representation in technopolitical communities.

I don't know if we're missing someone or if there's a part of the population that isn't participating. Of course, that's a very classist viewpoint, so I shouldn't be saying things like that. (Interview 29)

Several interviewees pointed out that socioeconomic stability influenced the capacity for technopolitical positioning and participation in this type of movement (e.g., "We're talking about the middle class" [Interview 17]).

For this reason, they were concerned about their profile showing up in the results of the questionnaire. Although they explicitly praised the values of freedom, accessibility, and diversity, the online context affected them insofar as they connected with a uniform social base.

The interviewees recognised that the Internet reflected the contemporary social context. Even with a free licence, they be- lieved that technology had to be accompanied by a desire for social change.

It's a pity because we're losing 50 per cent of the intellectual capacity of the planet [i.e. women]. If we rule out people of colour, immigrants, and so on, we're left with the usual arseholes. (Interview 16)

To their mind, racialisation, social origin, nationality, migratory status, functional diversity, sexual orientation, and gender identity reflected other inequalities that needed to be highlighted and addressed in technopolitical communities in order that they should become more diverse and more secure spaces for real social transformation.

\section{Conclusions}

Our aim has been to investigate the (in)visible internal barriers in free software and free culture communities and how they cope with them. This issue is especially relevant because it links to the core values of this movement. On the one hand, the importance of personal privacy and anonymity can contribute to the perception that these communities are not affected by the inequalities deriving from the identities of contributors (Collier \& Bear, 2012; Nafus, 2012). On the other hand, the access barriers to these communities contradict their vindication of the free distribution of knowledge and universal access to technologies (Benkler, 2006; Ostrom, 1990).

The communities expressed concern about the exclusion of specific sectors of society, not only in connection with our study's variables. In the interviews, they showed that they were aware of the intersectionality of the diverse social struggles in technological production (Costanza-Chock, 2018; Milan \& Treré, 2019), while also generally recognising the need to reflect on the inclusion of anti-racist, decolonial, LGBTQI, and class perspectives. Although online communities under-represent certain social groups, these inequalities are becoming an issue of visibility. This visibility is linked to the goals 
of collective change and social justice that Spanish free software communities have derived from their political interpretation of technologies during the $15 \mathrm{M}$ protests and earlier developments (Postill, 2016).

While for some interviewees underrepresentation was as a natural concern in their projects (Reagle, 2013), most of them recognised that the influence of external social movements had contributed to highlight these issues and to the quest for solutions. The impetus of the feminist movement is unusually explicit in communities that identify themselves as cyberfeminist and in which gender struggles are as relevant as the vindication of free technology (e.g., la_bekka, Akelarre Ciberfeminista).

The communities surveyed here show how (in)visibility is a valuable concept in analysing representation and its negotiation in social movements (Abdi \& Van Gilder, 2016; Magnusdottir \& Kronsell, 2015). However, strategies to achieve a broader diversity in their projects still have not been implemented. The interviewees proposed only partial solutions, such as the creation of codes of conduct to avoid situations of harassment or symbolic violence against women (e.g., concerning events open to the public such as Python España). As to gender, other collectives have created events and communities exclusively for women so as to highlight their contributions to free culture and free software.

Only larger communities have the wherewithal to create specific independent groups for women (e.g., pyladiesBCN). In line with studies such as those performed by Powell, Hunsinger, and Medlin (2010), the participants in these initiatives note that values such as collaboration and fostering personal ties are more developed in these specific spaces. They express a cultural dimension of women's presence in the collaborative creation of free code and copyleft content.

Some collectives have also modified their internal structure so as to be able to undertake different tasks, from press relations to mentoring newcomers, on a rotation basis. In this respect, the issue of (in)visibility, understood as the ability to have a media impact on the public sphere (Koopmans, 2004) has also been raised by free software communities, which identify with the tendency towards specific sociodemographic profiles regarding positions of leadership and representation in the media (Rohlinger et al., 2019). Such a division of labour and self-awareness of media (in)visibility are also examples of the values that guide communities in their daily practice.

The high educational level necessary for accessing these groups is also a visible and recognised concern. The skills required can differ widely depending on the community. While some require web text editing skills (Cuarto Propio en Wikipedia), an understanding of network infrastructure is prerequisite for others (Expansió de la Xarxa Oberta). The interviewees admitted the difficulties in participating in certain technical processes and using specific tools without prior knowledge or training (Coleman \& Golub, 2008; Jackson \& Kuehn, 2016). Although they claimed that having higher education was not tantamount to possessing the right knowledge (Himanen, 2001), they associated technical skills with a degree in telecommunications or computing.

The quantitative data obtained in our study corroborates the findings of previous research that has indicated the archetypal member profile of these communities is a male with a high educational level and technological specialisation (Ghosh et al., 2002). As to age, however, our results contradict the common view that the young make a significant contribution to free software and free culture. Although for the interviewees there was no generational problem, it is interesting to note that, according to one of their number, the younger generations have been born into a media ecosystem in which corporate social networks are places for socialising. Therefore, the critical view of technology of young people using computers in the 1990s has since changed (Margolis et al., 1999). Thus, technological skills do not necessarily go hand in glove with a technopolitical interest in or critical use of electronic devices and platforms. 
Further studies should inquire into the evolution of users' perceptions or social networking sites.

Our study has a number of limitations. As already noted, the interviewees mentioned additional (in)visibility issues (i.e., sexual orientation, ethnic background), which also defined the member profiles with access to the most innovative technologies. Furthermore, our results might have differed regarding gender (in)visibility if the interviewer had been a man. And, lastly, the different profiles of the respondents completing the quantitative questionnaire and those participating in the qualitative interviewees may have skewed our results.

The intersections that we have identified between technology and social struggles may also serve for analysing contemporary social movements, which have already been the object of study, as is the case with the research conducted by Toupin $(2014,2016)$ on the hacker movement. Regarding academic qualifications, future research should focus on the processes of prior empowerment and the planning of educational strategies that communities adopt to overcome the barriers to the participation of people with less formal education.

In the context of the identities that interact and participate in communities, (in) visibility is no minor issue in present-day society. The fast-paced development of technologies and the explosive growth of connectivity to the Internet are essential to understand how this new public sphere reflects dominant frameworks and agendas. Representativeness and visibility are relevant inasmuch as that they can include the demands of a wide range of contemporary social struggles, especially in communities seeking freedom and autonomy in technologically mediated spheres.

\section{Acknowledgements}

This paper has received funding from Banco Sabadell Foundation Research Grant Programme (2018).

\section{References}

Abdi, S., \& Van Gilder, B. (2016). Cultural (in) visibility and identity dissonance: Queer Iranian-American women and their negotiation of existence. Journal of International and Intercultural Communication, 9(1), 69-86. https://doi.org/10.1080/17513057. 2016.1120850.

Ander Egg, E. (2003). Repensando la investigación acción participativa: Comentarios y sugerencias [Rethinking participatory action research: Comments and suggestions]. Buenos Aires: Lumen.

Antin, J., Yee, R., Cheshire, C., \& Nov, O. (2011). Gender differences in Wikipedia editing. WikiSym '11: Proceedings of the $7^{\text {th }}$ International Symposium on Wikis and Open Collaboration (pp. 11-14). https://dl.acm. org/doi/10.1145/2038558.2038561.

Barbas, A., \& Postill, J. (2017). Communication activism as a school of politics: Lessons from Spain's Indignados movement. Journal of Communication, 67(5), 646-664. https://doi.org/10.1111/jcom.12321.

Barranquero, A., \& Montero, D. (2015). La elaboración de una cartografía sobre los medios del tercer sector en España: Descripción de un proceso de investigación colaborativa [The elaboration of a cartography on the third sector media in Spain. Description of a collaborative research process]. Revista Internacional de Pensamiento Político, 10, 17-25.

Bauman, Z., Bigo, D., Esteves, P., Guild, E., Jabri, V., Lyon, D., \& Walker, R. B. J. (2014). After Snowden: Rethinking the impact of surveillance. International Political Sociology, 8(2), 121-144. https://doi.org/10.1111/ ips.12048.

Benkler, Y. (2006). The wealth of networks: How social production transforms markets and freedom. New Haven: Yale University Press.

Calvo, D. (2018). Mapeo de comunidades de cultura libre en España [Mapping of free culture communities in Spain] [Data set]. University of Valladolid. Retrieved from http://uvadoc.uva.es/handle/ $10324 / 40964$.

Carr, N. (2008). The big switch: Rewiring the world, from Edison to Google. New York: Norton \& Co. 
Casas-Cortés, M. I., Osterweil, M., \& Powell, D. E. (2008). Blurring boundaries: Recognizing knowledge-practices in the study of social movements. Anthropological Quarterly, 81(1), 17-58. https://doi. org/10.1353/anq.2008.0006.

Castells, M. (2012). Networks of outrage and hope: Social movements in the Internet age. Cambridge: Polity Press.

Cea D’Ancona, M. Á. (1996). Metodología cuantitativa: Estrategias y técnicas de investigación social. [Quantitative methodology: Strategies and techniques of social research]. Madrid: Síntesis.

Christl, W., \& Spiekermann, S. (2016). Networks of control: A report on corporate surveillance, digital tracking, big data \& privacy. Vienna: Facultas.

Coleman, G. (2011). Hacker politics and publics. Public Culture, 23(3), 511-516. https:// doi.org/10.1215/08992363-1336390.

Coleman, G., \& Golub, A. (2008). Hacker practice: Moral genres and the cultural articulation of liberalism. Anthropological Theory, 8(3), 255-277. https://doi. org/10.1177/1463499608093814.

Collier, B., \& Bear, J. (2012). Conflict, criticism, or confidence: An empirical examination of the gender gap in Wikipedia contributions. Proceedings of the $\{A C M\} 2012$ Conference on Computer Supported Cooperative Work (pp. 383-392). https: / / doi. org/10.1145/2145204.2145265.

Costanza-Chock, S. (2018). Design justice: Towards an intersectional feminist framework for design theory and practice. $D e$ sign Research Society: Catalyst (pp. 1-14). https://doi.org/10.21606/drs.2018.679.

Cox, L., \& Flesher Fominaya, C. F. (2009). Movement knowledge: What do we know, how do we create knowledge and what do we do with it? Interface: A Journal for and about Social Movements, 1(1), 1-20.

Crenshaw, K. (1991). Mapping the margins: Intersectionality, identity politics, and violence against women of color. Stanford Law Review, 43(6), 1241-1299. https://doi. org/10.2307/1229039.

Cuesta, M., Font, J., Ganuza, E., Gómez, B., \& Pasadas, S. (2008). Encuesta deliberativa [Deliberative survey]. Madrid: Centro de Investigaciones Sociológicas.
Dahlberg, L. (2018). Visibility and the public sphere: A normative conceptualisation. Javnost-The Public, 25(1/2), 35-42. https://doi.org/10.1080/13183222.2018.1 418818.

Della Porta, D., \& Pavan, E. (2017). Repertoires of knowledge practices: Social movements in times of crisis. Qualitative Research in Organizations and Management: An International Journal, 12(4), 297-314. https:// doi.org/10.1108/QROM-01-2017-1483.

Durston, J., \& Miranda, F. (2002). Experiencias y metodología de la investigación participativa [Experiences and methodology of participatory research]. Santiago: CEPAL.

Fuchs, C. (2011). Web 2.0, prosumption, and surveillance. Surveillance \& Society, 8(3), 288-309.

Ghosh, R. (2005). Understanding free software developers: Findings from the FLOSS study. Maastricht: MERIT/Institute of Infonomics, University of Maastricht.

Ghosh, R. A., Glott, R., Krieger, B., \& Robles, G. (2002). Free/libre and open source software: Survey and study (FLOSS Final Report Part 4). Maastricht: University of Maastricht.

Giuri, P., Rullani, F., \& Torrisi, S. (2008). Explaining leadership in virtual teams: The case of open source software. Information Economics and Policy, 20(4), 305-315. https:// doi.org/10.1016/j.infoecopol.2008.06.002.

Graells-Garrido, E., Lalmas, M., \& Menczer, F. (2015). First women, second sex: Gender bias in Wikipedia. In Association for Computing Machinery (ed.), HT 2015 - Proceedings of the 26th ACM Conference on Hypertext and Social Media (pp. 165-174). https://doi.org/10.1145/2700171.2791036.

Hill, B. M., \& Shaw, A. (2013). The Wikipedia gender gap revisited: Characterizing survey response bias with propensity score estimation. PLoS ONE, 8(6), 1-5. https:// doi.org/10.1371/journal.pone.0065782.

Himanen, P. (2001). The hacker ethic and the spirit of the information age. London: Secker \& Warburg.

Howard, P. N. (2002). Network ethnography and the hypermedia organization: New media, new organizations, new methods. New Media \& Society, 4(4), 550-574. https://doi. org/10.1177/146144402321466813.

Jackson, S. K., \& Kuehn, K. M. (2016). Open source, social activism and "necessary 
trade-offs" in the digital enclosure: A case study of platform co-operative, loomio.org. tripleC, 14(2), 413-427.

Jordan, T. (1999). Cyberpower: The culture and politics of cyberspace and the Internet. London: Routledge.

Jordan, T. (2017). A genealogy of hacking. Convergence, 23(5), 528-544. https://doi. org/10.1177/1354856516640710.

Koopmans, R. (2004). Movements and media: Selection processes and evolutionary dynamics in the public sphere. Theory and Society, 33, 367-391. https://doi. org/10.1023/B:RYSO.0000038603.34963.de.

Lam, S. S. (Tony) K., Uduwage, A., Dong, Z., Sen, S., Musicant, D. R., Terveen, L., \& Riedl, J. (2011). WP: Clubhouse? An exploration of Wikipedia's gender imbalance. In Association for Computing Machinery (ed.), Proceedings of the $7^{\text {th }}$ International Symposium on Wikis and Open Collaboration (pp. 1-10). https://doi. org/10.1145/2038558.2038560.

Langman, L. (2006). From virtual public spheres to global justice: A critical theory of internetworked social movements. Sociological Theory, 23(1), 42-74. https:// doi.org/10.1111/j.0735-2751.2005.00242.x.

Lessig, L. (2004). Free culture: How big media uses technology and the law to lock down culture and control creativity. New York: The Penguin Press.

Lim, S., \& Kwon, N. (2010). Gender differences in information behavior concerning Wikipedia, an unorthodox information source? Library and Information Science Research, 32(3), 212-220. https://doi.org/10.1016/j. lisr.2010.01.003.

Lima Santos, L. (1983). La naturaleza de la investigación-acción [The nature of action research]. Lima: Celats.

Magnusdottir, G. L., \& Kronsell, A. (2015). The (in)visibility of gender in Scandinavian climate policy-making. International Feminist Journal of Politics, 17(2), 308-326. https://doi.org/10.1080/14616742.2014.8 96661.

Margolis, J., Fisher, A., \& Miller, F. (1999). Caring about connections: Gender and computing. IEEE Technology and Society Magazine, 18(14), 13-20. https://doi. org/10.1109/44.808844.
Milan, S., \& Treré, E. (2019). Big data from the south(s): Beyond data universalism. Television and New Media, 20(4), 319-335. https://doi. org/10.1177/1527476419837739.

Ministry of Education and Science (2006, May 4). Ley orgánica de educación [Education Act]. Boletín Oficial del Estado. Retrieved from https://www.boe.es/boe/ dias/2006/05/04/pdfs/A17158-17207.pdf.

Nafus, D. (2012). "Patches don't have gender": What is not open in open source software. New Media \& Society, 14(4), 669-683. https://doi. org/10.1177/1461444811422887.

Nosko, A., Wood, E., \& Molema, S. (2010). All about me: Disclosure in online social networking profiles: The case of Facebook. Computers in Human Behavior, 26(3), 406-418. https://doi.org/10.1016/j. chb.2009.11.012.

Ostrom, E. (1990). Governing the commons: The evaluation of institutions and collective action. Cambridge: Cambridge University Press.

Patil, V., \& Purkayastha, B. (2015). Sexual violence, race and media (in)visibility: Intersectional complexities in a transnational frame. Societies, 5(3), 598-617. https://doi. org/10.3390/soc5030598.

Postill, J. (2016). Freedom technologists and the future of global justice. In N. Buxton \& D. Eade (eds.), State of power 2016: Democracy, sovereignty and resistance (pp. 147163). Amsterdam: Transnational Institute.

Powell, W. E., Hunsinger, D. S., \& Medlin, B. D. (2010). Gender differences within the open source community: An exploratory study. Journal of Information Technology, XXI(4), 29-37.

Raynes-Goldie, K. (2010). Aliases, creeping, and wall cleaning: Understanding privacy in the age of Facebook. First Monday, 15(1). https://doi.org/10.5210/fm.v15il.2775.

Reagle, J. (2013). “Free as in sexist?”: Free culture and the gender gap. First Monday, 18(1/7). https://doi.org/10.5210/ fm.v18i1.4291.

Reagle, J., \& Rhue, L. (2011). Gender bias in Wikipedia and Britannica. International Journal of Communication, 5, 1138-1158. 
Reischl, G. (2008). El engaño Google: Una potencia mundial incontrolada en Internet [The Google hoax: An uncontrolled world power on the Internet]. Barcelona: Medialive Content.

Rheingold, H. (1993). The virtual community: Homesteading on the electronic frontier. Reading digital culture. Reading: AddisonWesley.

Robles, G., Reina, L. A., Serebrenik, A., Vasilescu, B., \& González-Barahona, J. (2014). FLOSS 2013: A survey dataset about free software contributors: Challenges for curating, sharing, and combining. In Association for Computing Machinery (ed.), 11th Working Conference on Mining Software Repositories, MSR 2014 Proceedings (pp. 396-399). https://doi. org/10.1145/2597073.2597129.

Rohlinger, D. A., Redmond, R. A., \& Stamm, T. (2019). Gender, age, and political legitimacy: Activist (in)visibility in broadcast news, 1970-2012. Journal of Women \& Aging, 1-25. Advanced online publication. https://doi.org/10.1080/08952841.2019.1 593774

Ruiz Olabuénaga, J. I. (2012). Metodología de la investigación cualitativa [Qualitative research methodology]. Bilbao: Deusto.

Sádaba, I., \& Gordo, Á. (2011). La indolencia tecnopolítica de las ciencias sociales [The technopolitical indolence of the social sciences]. Viento Sur, 117, 76-82.

Seymour, K. (2019). (In)visibility and recognition: Australian policy responses to 'domestic violence'. Sexualities, 22(5/6), 751-766. https://doi. org/10.1177/1363460716681465.

Sobieraj, S. (2010). Reporting conventions: Journalists, activists, and the thorny struggle for political visibility. Social Problems, 57(4), 505-528. https://doi.org/10.1525/ sp.2010.57.4.505.

Solove, D. J. (2001). Privacy and power: Computer databases and metaphors for information privacy. Stanford Law Review, 53, 1393-1462. https://doi. org/10.2307/1229546.

Stephansen, H. (2016). Understanding citizen media as practice: Agents, processes, publics. In M. Baker \& B. B. Blaagaard (eds.), Citizen media and public spaces:
Diverse expressions of citizenship and dissent (pp. 25-41). London: Routledge. Stoecker, R. (1995). Community, movement, organization: The problem of identity convergence in collective action. Sociological Quarterly, 36(1), 111-130.

Taraszow, T., Aristodemou, E., Shitta, G., Laouris, Y., \& Arsoy, A. (2010). Disclosure of personal and contact information by young people in social networking sites: An analysis using Facebook ${ }^{\mathrm{TM}}$ profiles as an example. International Journal of Media and Cultural Politics, 6(1), 81-101. https://doi.org/10.1386/macp.6.1.81/1.

Toret, J., @Datanalysis15m, Calleja, A., Miró, Ó. M., Aragón, P., Aguilera, M., \& Lumbreras, A. (2013). Tecnopolítica: La potencia de las multitudes conectadas. El sistema red $15 M$, un nuevo paradigma de la política distribuida [Technopolitics: The power of connected crowds. The 15M network system, a new paradigm of distributed politics]. Barcelona: IN3 Working Paper Series.

Toupin, S. (2014). Feminist hackerspaces: The synthesis of feminist and hacker cultures. Journal of Peer Production, (5). Retrieved from http://peerproduction.net/editsuite/ issues/issue-5-shared-machine-shops/ peer-reviewed-articles/feministhackerspaces-the-synthesis-of-feministand-hacker-cultures/.

Toupin, S. (2016). Gesturing towards "anticolonial hacking" and its infrastructure. Journal of Peer Production, (9). Retrieved from http://peerproduction.net/editsuite/ issues/issue-9-alternative-internets/ peer-reviewed-papers/anti-colonialhacking/.

Treré, E., \& Barranquero, A. (2018). Tracing the roots of technopolitics: Towards a North-South dialogue. In F. Sierra \& T. Gravante (eds.), Networks, movements and technopolitics in Latin America: Critical analysis and current challenges (pp. 43-63). New York: Palgrave.

Tufekci, Z. (2008). Can you see me now? Audience and disclosure regulation in online social network sites. Bulletin of Science, Technology \& Society, 28(1), 20-36. https:// doi.org/10.1177/0270467607311484.

Valles, M. S. (1999). Técnicas cualitativas de investigación social: Reflexión metodoló- 
gica y práctica profesional [Qualitative social research techniques: Methodological reflection and professional practice]. Madrid: Síntesis.

van Stekelenburg, J., Oegema, D., \& Klandermans, B. (2010). No radicalization without identification: How ethnic Dutch and Dutch Muslim web forums radicalize over time. In A. Azzi, X. Chryssochoou, \& B. Klandermans (eds.), Identity and Participation in Culturally Diverse Societies. A Multidisciplinary Perspective (pp. 256274). Hoboken: Wiley.
Vaserfirer, A. (2012). (In)visibility in lesbian and gay student organizing: The case of gay student services. Journal of Homosexuality, 59(4), 610-627. https://doi.org/10.1080/00 918369.2012.665706.

Wagner, C., Garcia, D., Jadidi, M., \& Strohmaier, M. (2015). It's a man's Wikipedia? Assessing gender inequality in an online encyclopedia. Proceedings of the Ninth International AAAI Conference on Web and Social Media (pp. 454-463). Retrieved from https:// www.sg.ethz.ch/media/publication files/10585-46528-1-PB.pdf. 